\title{
Editorial
}

\section{Transformación digital para la revolución industrial: el nuevo llamado para la U.D.C.A}

\author{
Germán Anzola Montero ${ }^{1}$
}

${ }^{1}$ Rector. Universidad de Ciencias Aplicadas y Ambientales U.D.C.A, (Dhttps://orcid.org/0000-0001-6075-2595

Cómo citar: Anzola Montero, G. 2019. Transformación digital para la revolución industrial: el nuevo llamado para la U.D.C.A. Rev.

U.D.C.A Act. \& Div. Cient. 22(1):e1228. https://doi.org/10.31910/rudca.v22.n1.2019.1228

Artículo de acceso abierto publicado por Revista U.D.C.A Actualidad \& Divulgación Científica, bajo una licencia Creative Commons CC BY-NC 4.0

Una perspectiva sagaz de la vida de hoy, se basa en una tecnología inteligente. Cambios rápidos en física, como robots inteligentes, drones autónomos, automóviles sin conductor, impresión 3D y sensores inteligentes; cambios digitales: Internet de objetos, de servicios, de datos e, incluso, de personas y cambios biológicos, como biología sintética y genética individual. Es, en general, la forma en que trabajamos, aprendemos y vivimos, que convierten a la tecnología en una fuerza crucial, para la competitividad económica y el desarrollo social.

La Educación Superior -en la cuarta revolución industrial- es una oportunidad compleja, dialéctica y emocionante que, potencialmente, puede transformar la sociedad en una mejor. Esta revolución está impulsada por la inteligencia artificial (AI), que transformará la forma de hacer las cosas, el modo de aprender y centrará todo en torno a las capacidades humanas, para responder a estos desafíos.

Hoy por hoy, es mucho lo que se predice acerca de cuál es el verdadero rol que debe desempeñar la Educación Superior, algunos con predicciones contradictorias, como que las máquinas harán el trabajo inteligente y no quedará nadie para enseñar; que el péndulo oscilará de nuevo hacia la metodología tipo conferencia; que esa facultad o programa serán reemplazados por dispositivos o que la tecnología en la academia hará pocos cambios significativos.

Las funciones sustantivas de la Educación Superior seguirán siendo las mismas; sin embargo, el objetivo es garantizar la calidad del aprendizaje, a través de la enseñanza, para permitir que los estudiantes obtengan los últimos conocimientos, a través de una Investigación exploratoria y aplicada, conducente al desarrollo y al sostenimiento de las sociedades, mediante la vocación de servicio.

Con su velocidad y amplitud, la cuestión planteada por las mega tendencias mencionadas y la cuarta revolución industrial subsiguiente para la Educación Superior, requiere repensar las estrategias comunes, para enfocarlas en puntos decisivos, como:

- Procesos asistidos de enseñanza, aprendizaje y formación

- Promoción de cursos masivos abiertos en línea (MOOCS)

- Cultivar el talento innovador

- Generalizar el aprendizaje mixto (Blended Learning)

- Innovación abierta

Es muy probable que algunos cambios sucedan de forma más acelerada que otros, pero el llamado es a migrar de programas "cargados de contenido", a modelos de aprendizaje más flexibles y aplicados. Las organizaciones más ágiles tienen una capacidad sostenida para responder rápida y eficazmente al cambio, por eso, la relevancia del compromiso, en todos los niveles de la Institución. La colaboración para crear una visión compartida, la cooperación como reciprocidad y la sincronización coordinada de la actividad, son críticas para este proceso.

En la actualidad, la reflexión en torno a la Cuarta Revolución Industrial nos convoca urgentemente, un fenómeno que no es ajeno a la Educación Superior en Colombia y que nos recuerda el llamado que, en nuestra región, tenemos al respecto. 
Las reflexiones estimadas en este editorial y algunas visiones expresadas por parte de Directivos de la Educación Superior fueron el tema central del Foro de Educación Superior Bogotá 2019 "La Educación Superior ante la Transformación Digital, para la Cuarta Revolución Industrial", evento organizado por la Universidad de Ciencias Aplicadas y Ambientales U.D.C.A, la Asociación de Universidades de América Latina y el Caribe para la Integración AUALCPI, Virtual Educa y la Universidad El Bosque, con el apoyo de la Asociación Colombiana de Universidades ASCUN.

Evidentemente, durante el Foro, surgieron interrogantes, como: i) la transformación que está generando la Cuarta Revolución Industrial ¿está causando cambios en los aprendizajes? ii) Las Universidades de la región y del mundo, ¿ya iniciaron su desafío frente al momento crucial de la innovación digital? Para responder a estas inquietudes, nada mejor que extraer de la presentación Magistral del CEO INNOVIVIR y Director de Programas Corporativos Pacífico Business School, Edgar Cateriano Castello (2019), al referirse a las etapas de la Transformación digital en las organizaciones:

Primera etapa -Lo de siempre: Tradicionalmente, se trabaja con lo mismo, pensando que se da solución a los cambios del mundo digital. Segunda etapa-Presente y activo: A pesar que existe un desequilibrio en la asignación de recursos para la implementación digital, se optimizan los procesos digitales.

Tercera etapa-Formalizado: Se experimenta, se ejecuta y surgen cambios a favor de la tecnología.

Cuarta etapa -Estratégico: Se formulan estrategias esfuerzos, responsables y recursos y se consolidan grupos de trabajo.

Quinta etapa -Convergente: Se consolida una infraestructura -roles, modelos, procesos-, con una ruta a la transformación digital.

Sexta etapa-Innovadory adaptable: "La transformación digital se convierte en el camino. Se reconoce que el camino es constante. Se establece un nuevo ecosistema para identificary actuar con la tecnología y las tendencias del mercado, en pilotos o gran escala".

Acompañando estas etapas, un listado de valores asociados a la transformación. Algunos de ellos: adaptabilidad, desarrollo profesional, pasión, autodisciplina, entusiasmo, reputación, competitividad, conocimiento, democracia, involucración, vocación y muchos más.

Frente a este panorama, las universidades colombianas y de la región deben asumir cambios significativos, impulsados por las nuevas tendencias de la tecnología, enmarcadas hacia la digitalización, una herramienta que le permite innovar en el modo del aprendizaje en la Educación Superior: "Pasamos de entender la tecnología como un robusto cúmulo de infraestructura para concebirla como un complejo e interconectado ecosistema que habilita el aprendiraje digital. La atención no recae más en la tecnología misma, abora se centra en los alumnos y usuarios, así como las experiencias de aprendizaje que permite" (Moreno, 2019).

El mismo autor, después de un análisis de la revolución de la digitalización en las Universidades, algunas de Latinoamérica, concluyó que, si los estudiantes nacieron ya digitalizados, pues las Instituciones debe brindarles estas mismas condiciones: cursos online, campus universitarios virtuales, es decir, generar entornos competitivos.

El documento The 2017 State of Digital Transformation (Solis, 2017), sugiere algunas ideas clave para impulsar la transformación digital: 1) Se debe invertir en comprender al cliente digital; 2) Al convertirse la Institución en una compañía de tecnología, el esfuerzo debe ser de todos los estamentos que componen la Universidad; 3) La percepción de que la transformación digital es muy costosa y no una inversión, genera retrasos e inconvenientes y 4) Se debe invertir en nuevos talentos digitales.

Frente a esta situación, fue que el Foro propuso abrir espacios y talleres, donde expertos y autoridades académicas abordaran temáticas, como:

- La Educación Superior como actor fundamental de la Agenda 2030.

- Capital Humano con habilidades 4.0, gestión del conocimiento y cultura de innovación.

- Transformación del currículo, investigación innovadora y responsable, fortalecimiento de alianzas público-privadas.

- Diagnóstico del fenómeno en América Latina y el Caribe, una óptica regional.

En fin, las discusiones alrededor de este tema, darán cuenta que el cambio ya está aquí y que la necesidad de afrontarlo, es inminente, no solo en Colombia, sino en Latinoamericana y el Caribe, dándonos una óptica regional de las acciones a emprender.

Este es el inicio de un ciclo constante de reflexiones, que nos permitirá cooperar en torno a nuestro noble propósito: generar capital humano con habilidades 4.0.

\section{REFERENCIAS}

1. CATERIANO CASTELlO, E. 2019. Liderazgo en transformación. Valores y habilidades para momentos de cambio. Pacifico Business School. Conferencia magistral. La Educación Superior ante la Transformación Digital, para la Cuarta Revolución Industrial. Bogotá, D.C., Colombia, 10 de mayo de 2019.

2. MORENO, J.L. 2019. 3 desafíos de las instituciones de educación superior ante la transformación digital. Disponible desde Internet en: https://virtualeduca.org/mediacenter/3desafios-de-las-instituciones-de-educacion-superior-antela-transformacion-digital/ (con acceso 21/05/2019).

3. SOLIS, B. 2017. The 2017 State of Digital Transformation. Altimeter Prophet. Disponible desde Internet en: https:// insights.prophet.com/state-digital-transformation-2017 (con acceso 21/05/2019). 